\title{
Sobre os fundamentos da psicoterapia de base analítico-existencial, segundo Ludwig Binswanger
}

Mário Eduardo Costa Pereira

Em seu livro mais recente, dedicado ao estudo dos fundamentos da psicoterapia, Pierre Fédida (2001) faz o seguinte comentário a respeito do artigo "Sobre a psicoterapia”, de Binswanger:

Em seu texto de 1935, "Sobre a psicoterapia” Ludwig Binswanger designou o fundamento ontológico e existencial da psicoterapia nesse Menschsein - esta "estrutura do ser-homem enquanto ser-no-mundo [in-der-Welt-sein] (Heidegger), o ser com e pelo outro" (ibid.: 166).

De fato, o artigo de Binswanger, traduzido neste número da Revista Latinoamericana de Psicopatologia Fundamental, constitui uma contribuição maior do grande psiquiatra suíço para a elucidação da estrutura transcendental na qual se dá o encontro psicoterápico, além de ser uma excelente introdução para todo aquele interessado em compreender a especificidade da proposta psicoterápica de base analítico-existencial.

Fédida acrescenta que, para Binswanger, era decisivo terse em mente que a psicoterapia colocava em jogo duas existências e dois existentes e que seu objetivo maior é o de liberar o ser do "isolamento cego do idios cosmos" de tal maneira que ele possa ser capaz de participar do koinos cosmos da comunidade.

Oriundo de uma formação psiquiátrica junto a Bleuler e a Jung no Burgholzly, e tendo tido um contato intenso e precoce 
com a nascente psicanálise freudiana, Binswanger realizou um percurso caracterizado por uma adesão inicial à proposta clínica psicanalítica, embora fosse gradualmente se afastando das proposições metapsicológicas de Freud. À medida que seus estudos da fenomenologia de Husserl e da ontologia fundamental de Heidegger iam se aprofundando, Binswanger se tornava cada vez mais crítico em relação à teorização do "inconsciente" e do "aparelho psíquico" de Freud, a quem acusava de ter "pouca exigência metafísica” (Gillibert: 1995). Para Binswanger, o método científico de Freud acabava por reduzir o ser humano a um esquema ou a um sistema. Para modificar esse estado de coisas seria necessário uma pesquisa antropológica que não encerrasse o homem em categorias biológicas ou psicológicas, mas que buscasse compreendê-lo a partir daquilo que especifica seu ser (Fichtner, 1995: 32).

Dessa forma, o projeto de Binswanger consistia, antes de tudo, em prover a psiquiatra e a psicopatologia de um fundamento epistemológico e metodológico que pudesse dar conta da dimensão propriamente existencial do homem, o que o levou a uma singular aproximação de Freud com Heidegger, da psicanálise com a fenomenologia. Surgiria, assim, a proposta de uma análise existencial e sua concepção da clínica e da psicoterapia iria, aos poucos, portando as marcas dessa exigência ético-intelectual.

... se a psicanálise de Freud ou as doutrinas de Jung surgem de uma insatisfação face a psicoterapia da época, se assim elas devem sua edificação e sua elaboração a impulsos e objetivos principalmente psicoterápicos, a direção de pesquisa analítico-existencial em psiquiatria surgiu [por sua vez] da insatisfação quanto aos projetos de compreensão científica da psiquiatria da época (Binswanger, 1970: 115).

Com essas palavras, Binswanger situa com clareza sua visão das diferentes vocações da psicanálise e da análise existencial: enquanto a primeira teria se originado de uma preocupação terapêutica, a análise existencial teria sido inicialmente um novo método de pesquisa, buscando lançar as bases científicas da psicopatologia e da psiquiatria. Só secundariamente ela teria se organizado como proposta de tratamento. Compreende-se, dessa forma, o caráter mais elaborado e completo da psicopatologia - e mesmo do estudo da estrutura transcendental a priori da situação terapêutica - decorrentes da análise existencial de Binswanger, do que o de suas teorizações propriamente psicoterápicas. Por outro lado, vemos que a concepção binswangeriana de psicoterapia consistirá numa tentativa de aprimoramento da psicanálise, pelo esforço de submeter os fundamentos de sua prática às exigências de uma antropologia fenomenológica.

Assim, para que se possa melhor delinear a proposta de psicoterapia analíticoexistencial, é necessário que se situe previamente o corte instituído pela Daseinanalyse binswangeriana na tradição médica e psiquiátrica da psicopatologia. 
No contexto de sua Daseinanalyse e de sua antropologia fenomenológica, Binswanger insistiu inúmeras vezes na necessidade de se especificar o campo da psicopatologia em relação ao das ciências naturais. Em sua famosa conferência de 1924, intitulada "Função vital e história interior da vida” (1971: 49-77), Binswanger busca mostrar que estas "vêem no homem um organismo fisiopsíquico, um sistema de funções de ordem orgânica ligadas a processos naturais, um decurso de acontecimentos no tempo.” Por outro lado, a antropologia fenomenológica - segundo seu ponto de vista, a disciplina que deveria fundar a psicopatologia e a psiquiatria vê no homem "um ser pessoal que vive sua vida e cuja continuidade (...) se desdobra em história” (Kuhn \& Maldiney, 1971: 12). Na referida conferência, Binswanger reconhece explicitamente sua dívida metodológica em relação à distinção estabelecida por Jaspers entre relações de causalidade e de compreensão no campo do acontecer psíquico, as primeiras referindo-se a fatos concretos que estabelecem conjunções constantes com o surgimento de certos estados mentais e, as segundas, visando dar conta do encadeamento do psíquico que gera o psíquico, de uma forma que nos é compreensível.

A psicopatologia aparece, então, como a disciplina onde se encontram esses dois horizontes metodológicos distintos. Considerando o problema das relações entre o físico e o psíquico como intransponível, Binswanger propõe que se examine, em seu lugar, a questão mais fundamental: aquela do Ser e das relações do fenômeno psicopatológico com a existência daquele que o padece. Dessa forma, a análise existencial abriria à psiquiatria a possibilidade de um olhar sobre a totalidade da existência do homem.

A dimensão histórica, anteriormente evocada, é decisiva no pensamento binswangeriano, na medida em que este se apóia na Daseinanalytik de Heidegger para construir suas próprias bases teóricas e metodológicas de abordagem da psicopatologia.

Em Ser e tempo, de 1927 (portanto posterior à primeira edição da Psicopatologia Geral, de Jaspers), Heidegger desenvolve sua analítica do Dasein, como uma interpretação ontológica do sentido de ser. O filósofo alemão focaliza sua análise no ser dos entes enquanto tal e não pela via da metafísica clássica que recorre à descrição e classificação das características definidoras do existir dos entes. Nessa perspectiva, o termo Dasein refere-se ao existir humano, que se dá como um acontecer (sein) que se realiza aí $(D a)$, já jogado no mundo ${ }^{1}$. É o próprio existir que constitui o "aí” em que se dá a existência e nesse sentido Dasein pode ser pensado não ape-

1. A esse respeito, a dissertação de Ida E. Cardinalli intitulada “A teoria da esquizofrenia de M. Boss”, em fase de conclusão na PUC de São Paulo, examina a incidência do pensamento de Heidegger na constituição da Daseinanalyse. 
nas como Ser-aí, mas, como sugere Zeljko Loparic, Ser-o-aí, a clareira que permite $\mathrm{o}$ acolhimento daquilo que se dá enquanto experiência de mundo.

A partir daí, a temporalidade e a historicidade terão importância capital na análise heideggeriana do Dasein. Toda a possibilidade de compreensão do existir humano dependerá da temporalidade, enquanto continuidade histórica e enquanto finitude. É por esse motivo que a abordagem daseinanalítica de Binswanger reservará um espaço tão importante a essas duas dimensões.

Heidegger distingue os planos ôntico e ontológico, designando com o primeiro termo plano relacionado à elucidação da existência do Dasein e, com o segundo, a apresentação das estruturas existenciais do ser. Dessa forma, as dimensões fundamentais constituintes do Dasein (denominadas existenciais) são a temporalidade, a espacialidade, o ser-com-o-outro, a disposição, a compreensão, o cuidado (Sorge), a queda e o ser-para-a-morte. A existência do Dasein dá-se dentro dessas dimensões e caracteriza-se pela abertura do mundo e do sentido do ser e pela liberdade. As condições de possibilidade de uma existência dependerão, assim, dos horizontes da própria condição humana.

Na apropriação que Binswanger faz do pensamento heideggeriano, para aplicálo à sua Daseinanalyse no campo da psicopatologia, o emprego do método fenomenológico não visa apenas descrever as vivências mórbidas e os encadeamentos psíquicos ou naturais que levaram a seu surgimento - como faz Jaspers - mas, antes, de apreender as condições particulares de existência de um indivíduo singular, em relação aos existenciais descritos por Heidegger no plano ontológico. O método psicopatológico de Binswanger visa descrever a experiência de mundo e as condições de existência tal como estas se dão nas circunstâncias particulares de cada Dasein. Trata-se de uma abordagem fenomenológica, no sentido de que depende da abertura à experiência concreta do outro, mas, ao mesmo tempo, volta-se às estruturas priori e transcendentais da existência, visando situar a organização específica daquele indivíduo, enquanto Dasein, face a seus existenciais. Trata-se, portanto, de descrever o mundo a partir da perspectiva e das possibilidades daquela existência singular.

Com esse arcabouço teórico em mente, ainda que rudimentar, torna-se possível situar em grandes linhas a proposta de psicoterapia analítico-existencial de Binswanger.

No mesmo artigo sobre análise existencial e psicoterapia anteriormente citado - um texto de 1954, ou seja, de um período de maturidade do pensamento binswangeriano -, são apresentadas cinco diretrizes básicas da psicoterapia sobre uma base analítico-existencial:

1. Ela deve explorar a história de vida do paciente, como o faria qualquer outra abordagem psicoterápica, visando compreendê-la não por meio de categorias teóricas abstratas, mas "como flexões da estrutura total do ser-no-mundo". 
2. Visa-se não apenas o insight, mas sobretudo provocar uma verdadeira reviravolta existencial, por intermédio de “um aprender pela experiência” na situação terapêutica. Aqui, o terapeuta é comparado a um guia de montanhas competente, "que conhece o terreno em questão" e que avança com o turista que, apavorado diante da amplidão incerta daqueles espaços, "não ousa mais dar um passo adiante ou para trás.”2

3. Quanto à estruturação da relação terapeuta-paciente, Binswanger sustenta que não se trata de alguém em posição de sujeito face a um objeto sobre o qual será aplicada a teoria ou a terapia. Ao contrário, o terapeuta deve propiciar que o paciente veja nele um parceiro no ser-aí. Dessa forma, a situação terapêutica deve constituir um encontro "sobre o abismo do ser-aí". Busca-se um "ser-com”, o que constitui a estrutura do "ser-junto" (ou amor), em uma temporalidade de um presente intrínseco, legitimadora da autenticidade do encontro, absolutamente original, fora das repetições do passado e aberta às possibilidades do futuro.

4. Quanto ao manejo dos sonhos, Binswanger vê na experiência onírica uma dimensão central na psicoterapia analítico-existencial. Segundo o psiquiatra suíço, o sonho - a despeito de sua forma por vezes confusa ou mesmo bizarra - comporta a mesma estrutura existencial da vida de vigília do sonhador. Trata-se apenas de uma das apresentações do Dasein: “... é precisamente com o auxílio da estrutura dos sonhos que [o analista existencial] pode mostrar ao doente, primeiramente, a estrutura de seu ser-no-mundo em geral; e sobre essa base, ele pode, em segundo lugar, libertá-lo para todo o poder-ser do Dasein". ${ }^{3}$

5. Binswanger reconhece que a psicoterapia de base analítico-existencial não pode prescindir de outros métodos psicoterapêuticos já consagrados. Contudo, ela só pode agir, em sua especificidade, abrindo ao homem a compreensão da estrutura de seu Dasein humano.

Em sua proposta mais radical, a psicoterapia de base analítico-existencial constitui uma tentativa de abrir certas formas de existir - fechadas, repetitivas e que acarretam sofrimento inútil e incapacidade de auto-realização - a novas possibilidades estruturais de existência.

Nessa perspectiva, o problema do sentido ganha uma dimensão maior no processo terapêutico. Como bem o demonstra Pierre Fédida (1970), em seu prefácio ao livro Análise existencial e psicanálise freudiana - que reúne textos de Binswanger tratando da psicoterapia, da psiquiatria e de Freud -, o caráter não tematizável do Dasein constitui uma dimensão incontornável para a organização da situação psicoterapêutica. A irredutibilidade do Dasein a um discurso constitui sua própria con- 
dição de possibilidade de transcendência. A fixação de um sentido já consistiria por si mesma em uma organização psicopatológica na medida que institui "uma limitação da presença ou, ainda, sua projeção em uma representação esvaziada de toda a transcendência” (ibid.: 31). A conseqüência clínica de tal perspectiva, conclui Fédida, é a de que "interpretar não é [...] apenas traduzir de uma linguagem a outra; nem mesmo fixar o sentido de uma palavra em uma significação tematizada. Tratase de permitir que o sentido se mova e circule sob as expressões diversas e múltiplas que a linguagem empresta para lhe conferir corpo e vida” (ibid.: 20).

O esforço ético de buscar continuamente que a teorização do psicopatológico e que a técnica da clínica não sufoquem a abertura da existência à transcendência: eis aí, talvez, uma síntese bastante pertinente da proposta de Binswanger no campo da psicoterapia.

\section{Referências bibliográficas}

Binswanger, L. Analyse existentielle et psychothérapie. In Analyse existentielle et psychanalyse freudienne: discours, parcours, et Freud. Paris: Gallimard, 1970.

BINSWANGER, L. Fonction vitale et histoire intérieure de la vie. In Introduction à l'analyse existentielle. Paris: Les Éditions de Minuit, 1971.

FÉdidA, P. Préface. In Binswanger, L. Analyse existentielle et psychanalyse freudienne: discours, parcours, et Freud. Paris: Gallimard, 1970.

FÉDIDA, P. Des bienfaits de la dépression: éloge de la psychothérapie Paris: Éd. Odile Jacob, 2001.

Fichtner, G. Introduction. In Freud, S. \& Binswanger, L. Correspondance 1908-1938, Paris: Calmann-Lévy, 1995.

Gillibert, J. Dialogues d'ombre: La psychanalyse et la phénoménologie - Freud et Binswanger. In Freud, S. \& Binswanger, L. Correspondance 1908-1938. Paris: Calmann-Lévy, 1995.

HeidegGer, M. (1927). Être et temps. Paris: Gallimard, 1986.

Kunn, R. \& Maldiney, H. Préface. In Binswanger, L. Introduction à l'analyse existentielle. Paris: Les Éditions de Minuit, 1971. 